http://jmscr.igmpublication.org/home/ ISSN (e)-2347-176x ISSN (p) 2455-0450 crossref DOI: https://dx.doi.org/10.18535/jmscr/v8i11.53

\title{
Comparative evaluation of King Vision Video laryngoscope and McCoy laryngoscope for tracheal intubation in patients with immobilized cervical spine: a prospective randomized study
}

Authors

\author{
Dr Pasupunuri Sharath Chandra ${ }^{1}$, Dr Sarfaraz Ahmad ${ }^{2}$, Dr Gopal Krishan ${ }^{3}$, \\ Dr Rampal Singh ${ }^{4}$, Dr Malti Agarwal ${ }^{5}$, Dr Kaustab Singh ${ }^{6}$ \\ ${ }^{1}$ Junior Resident, Department of Anaesthesiology, Rohilkhand Medical College, Bareilly \\ ${ }^{2}$ Assistant Professor, Department of Anaesthesiology, Rohilkhand Medical College, Bareilly \\ ${ }^{3}$ Associate Professor, Department of Anaesthesiology, Rohilkhand Medical College, Bareilly \\ ${ }^{4}$ Professor, Department of Anaesthesiology, Rohilkhand Medical College, Bareilly
}

${ }^{5}$ Professor \& Head of Department, Department of Anaesthesiology, Rohilkhand Medical College, Bareilly

${ }^{6}$ Junior Resident, Rohilkhand Medical College And Hospital, Bareilly

*Corresponding Author

Dr Sarfaraz Ahmad

\begin{abstract}
Background and Aims: It is challenging even to the most experienced anaesthesiologist to intubate in patients with restricted movement of the cervical spine. The randomized studies comparing King Vision video laryngoscope and McCoy laryngoscope are very limited. Therefore, we planned to study a comparative evaluation of King Vision video laryngoscope and McCoy laryngoscope for tracheal intubation in patients with immobilized cervical spine

Method: This was a prospective randomized study, carried out in patients posted for elective surgery.60 patients were randomly divided in two groups comprising 30 patients each of ASA Grade I or II, age 18$60 y r s$, either sex and weighing 45-80 kg under General Anaesthesia. Induction was done with inj. propofol $2.0 \mathrm{mg} \mathrm{kg-1/iv} \mathrm{and} \mathrm{inj.} \mathrm{succinylcholine} 1.5 \mathrm{mg} \mathrm{kg}-1$ /iv were used as muscle relaxant and Intubation was done using/applying standard protocol/technique with either King Vision video laryngoscope or McCoy laryngoscope.

Result: The demographic variables such as age, sex and ASA were similar in both the groups. There was no statistically significant difference. Mean intubation time of patients in Group A was $16.9 \pm 3.5$ sec and in Group B was $19.3 \pm 5.1$ sec. The mean intubation time was less in Group A patients and was statistically significant $(p=0.021)$. There was a statistically significant difference in POGO score of patients in between Group A and Group B ( $<0.001)$. There was no statistically significant difference in IDS of patients in between Group $A$ and Group $B(p=0.077)$. The mean arterial pressure was better in Group A although, there was no statistically significant difference.

Conclusion: We conclude that the King Vision video Laryngoscope is superior to the McCoy laryngoscope if cervical immobilization is anticipated.
\end{abstract}




\section{Introduction}

All anaesthesiologists should be well trained in different airway management techniques to decrease peri-operative mortality and morbidity.

In direct laryngoscopy for the visualization of the glottis alignment of oro-pharyngeal-laryngeal axis is required which is a difficult technical skill to acquire and maintained in all conditions. In trauma patients where cervical spine fracture is suspected airway management is a key concern. Application of cervical collar or manual inline stabilization (MILS) has become the quality of care in these patients for prevention of cord injury during endotracheal intubation. ${ }^{1}$

To reduce the cervical spine mobility during intubation, various manoeuvres and devices are introduced. The Advanced Trauma Life Support (ATLS) guidelines recommend the application of a rigid cervical collar or Manual Inline Stabilization (MILS) during laryngoscopy and intubation. The manual inline stabilization reduces cervical spine movement during laryngoscopy but it also decreases the laryngeal view making it difficult intubation. The use of a cervical collar and application of cricoid pressure further reduces the laryngeal view. ${ }^{1}$

The video laryngoscopes are gaining popularity in recent years. Video laryngoscopes show the view of the glottis from a video camera which is present near the tip of the laryngoscope blade and projected in a screen. It provides easy visualization of the vocal cords without direct line of sight. The video assisted laryngoscopy should be initial approach if difficult intubation is anticipated as per ASA recommendations. ${ }^{2}$

It is challenging even to the most experienced anaesthesiologist to intubate in patients with restricted movement of the cervical spine. Tracheal intubation must be performed very carefully in patients with cervical spine fractures or other cervical pathology to prevent cord damage. The application of semi rigid cervical collar or manual inline stabilization of the cervical spine may result in poor laryngeal view on standard laryngoscopy leading to difficult intubation as cervical movements are restricted. ${ }^{3,4}$

In cervical immobilized patients McCoy laryngoscope (Penlon) is used as it is designed with a hinged tip which elevates the epiglottis during laryngoscopy where neck movement if minimum. It is commonly used to facilitate endotracheal intubation when the view of the glottic opening is restricted. ${ }^{5}$

The King Vision video laryngoscope has two types of blades channelled blade and non channelled blade. The display is an organic light emitting diode (OLED) design with good clarity and resolution. Minimum of $18 \mathrm{~mm}$ mouth opening is required in one with channel while minimum $13 \mathrm{~mm}$ mouth opening is required in one without channel.10 The King Vision video laryngoscope is the latest among the long series of devices that provide the "perfect view" for intubation via use of video and digital technology. ${ }^{6}$

As the randomized studies comparing King Vision video laryngoscope and McCoy laryngoscope are very limited. Therefore, we planned to study a Comparative evaluation of King Vision video laryngoscope and McCoy laryngoscope for tracheal intubation in patients with immobilized cervical spine, after their approval for participating in the study.

\section{Methodology}

Type of study - A prospective randomized study,

Sample Size - 60 patients were randomly divided in two groups Group A and Group Beach comprising 30 patients.

Time of Study: One year starting from November 2018 to October 2019.

Inclusion Criteria: American society of Anaesthesiologist (ASA) grade I or II , age 18$60 \mathrm{yrs}$, either sex ,weighing 45-80 kg and posted for elective surgery of different specialities.

Exclusion Criteria: Patient refusal for procedure, patients with ASA GRADE >II, possibility of difficult intubation, emergency surgery, full stomach, obesity $($ BMI $>30 \mathrm{~kg} / \mathrm{m} 2)$, cardiovascular 
diseases and uncontrolled hypertension, high intra cranial pressure (ICP) and patient's with contraindications for insertion of supraglottic devices.

Methodology of the study was according to ethical principles for medicine research involving human subjects outlined in the declaration of Helsinki.

Thorough pre-anaesthetic check-up was done and informed written consent for participation in the study was taken. The patients were randomly divided into two groups: Group "A" and "B". In Group "A" King Vision video Laryngoscope was used and in Group "B" McCoy laryngoscope was used to intubate the patient. Tab Ranitidine 150 $\mathrm{mg}$ and Tab Alprazolam $0.25 \mathrm{mg}$ was given orally, the night before surgery.

On the day of surgery, IV drip was started $30 \mathrm{~min}$ before surgery. Monitor was attached and baseline readings were taken. Patient was premedicated with Inj. Ranitidine $50 \mathrm{mg} / \mathrm{iv}$, Inj. Ondansetron 4 $\mathrm{mg}$ /iv, Inj. Glycopyrrolate $0.2 \mathrm{mg} / \mathrm{iv}$, Inj. Midazolam $1 \mathrm{mg} / \mathrm{iv}$, Inj. Butorphanol $1 \mathrm{mg} / \mathrm{iv}$. Induction was done with inj. propofol $2.0 \mathrm{mg} \mathrm{kg-}$ $1 / \mathrm{iv}$ and inj. succinylcholine $1.5 \mathrm{mg} \mathrm{kg}-1$ /iv was used as muscle relaxant and Intubation was done using/applying standard protocol/technique with either King Vision video laryngoscope or McCoy laryngoscope. Confirmation of bilateral ventilation was done by adequate chest rise, auscultation and end tidal $\mathrm{CO}_{2}\left(\right.$ Et $\left.\mathrm{CO}_{2}\right)$. All indices pertaining to the act of intubation was recorded\& entered in the designated proforma. intubation time, number of attempts, success rates in 1st and 2nd attempts, successful intubations, any mucosal trauma, oesophageal intubations, change of performer, POGO, Cormack and Lehane score and IDS were studied and heart rate, systolic blood pressure, diastolic blood pressure, mean arterial blood pressure and arterial $\mathrm{O} 2$ saturation were recorded after induction, then immediately after intubation, and subsequently at 1 minute, 3 minutes, 5 minutes and 10 minutes after intubation. Maintenance was done with $\mathrm{O} 2$ and $\mathrm{N} 2 \mathrm{O}$ in the ratio 40:60, $0.8 \%$ Isoflurane and intermittent inj. vecuronium.
At the end of the surgery reversal was done with inj. neostigmine $0.05 \mathrm{mg} \mathrm{kg}-1 / \mathrm{iv}$ and inj. glycopyrrolate $0.008 \mathrm{mgkg}-1 / \mathrm{iv}$. Pharyngo-tracheal suction was done before extubation. Amount of blood loss and fluid given was assessed. After the patient is able to keep his eyes open, elevate head and breathe normally, he/she was shifted to postoperative room. Any complications, side effects and adverse effects up to $24 \mathrm{hrs}$ postoperatively wasnoted.

\section{Results}

The demographic variables such as age, sex and ASA were similar in both the groups. There was no statistically significant difference. (Table-1)

The successful intubation rate was $100 \%$ in both the Group A and Group B. 1st attempt success rate in Group A was 97\% and in Group B was 93\%. 2nd attempt success rate was $100 \%$ in both the Groups. (29/30) patients proceed in 1st attempts and (1/30) in 2nd attempt in Group A and (28/30) patients proceed in 1 st attempt and (2/30) in 2 nd attempt in Group B. There was no statistically significant difference in successful number of attempts of patients in either groups $(p=0.553)$. (Table-2)

Mean intubation time of patients in Group A was $16.9 \pm 3.5 \mathrm{sec}$ and in Group B was $19.3 \pm 5.1 \mathrm{sec}$. The mean intubation time was less in Group A patients and was statistically significant ( $\mathrm{p}=$ 0.021). (Figure-1)

14 patients have $100 \%$ POGO score, 13 have 50$100 \%$ and 3 have $<50 \%$ POGO score in Group A and 8 patients have $100 \%$ POGO score, 8 have 50 $100 \%$ and 14 have $<50 \%$ POGO score in Group B. There was a statistically significant difference in POGO score of patients in between Group A and Group B $(p<0.001)$. (Figure-2)

14 patients have 0 IDS, 11 patients have $<5$ IDS score and 5 patients have $>5$ IDS in Group A and 9 patients have 0 IDS, 8 patients have $<5$ IDS and 13 patients have > 5 IDS in Group B. There was no statistically significant difference in IDS of patients in between Group A and Group B $(p=0.077)$. (Figure-3) 
The mean arterial pressure was better in Group A difference. (Figure-4) although, there was no statistically significant

Table-1: Demography data in Group A and Group B

\begin{tabular}{|l|c|c|c|}
\hline Parameter & Group A & Group B & $p$ value \\
\hline Age(years) Mean \& range & $38.1 \pm 9.5$ & $36.6 \pm 9.3$ & 0.549 \\
\hline Gender (male/female) & $20 / 10$ & $18 / 12$ & 0.59 \\
\hline Weight(kg) (mean and range) & $57.6 \pm 7.9$ & $56.8 \pm 8.0$ & 0.686 \\
\hline $\begin{array}{l}\text { ASA (STATUS) } \\
1 / 2\end{array}$ & $21 / 9$ & $20 / 10$ & 0.78 \\
\hline
\end{tabular}

Table-2: Intubation success rate, time and airway complications of patients in Group A and Group B

\begin{tabular}{|c|c|c|c|}
\hline Parameter assessed & $\begin{array}{c}\text { Group A } \\
(\mathbf{n}=\mathbf{3 0})\end{array}$ & $\begin{array}{c}\text { Group B } \\
(n=30)\end{array}$ & $p$-value \\
\hline Successful intubation & $30(100 \%)$ & $30(100 \%)$ & \\
\hline $1^{\text {st }}$ attempt success rate & $97 \%$ & $93 \%$ & \\
\hline $2^{\text {nd }}$ attempt success rate & $100 \%$ & $100 \%$ & \\
\hline No of attempts $1 / 2 / 3$ & $29 / 1 / 0$ & $28 / 2 / 0$ & 0.553 \\
\hline Intubation time (seconds) & $16.9 \pm 3.5$ & $19.3 \pm 5.1$ & $0.021 *$ \\
\hline Mucosal trauma Y/N & $0 / 0$ & $1 / 0$ & \\
\hline Oesophageal intubation Y/N & $0 / 0$ & $0 / 0$ & \\
\hline \multicolumn{4}{|l|}{ POGO Score } \\
\hline $100 \%$ & 14 & 8 & \multirow{3}{*}{$<0.001 *$} \\
\hline $50-100 \%$ & 13 & 8 & \\
\hline$<50 \%$ & 3 & 14 & \\
\hline \multicolumn{4}{|l|}{ IDS } \\
\hline 0 & 14 & 9 & \multirow[t]{3}{*}{0.077} \\
\hline$<5$ & 11 & 8 & \\
\hline$>5$ & 5 & 13 & \\
\hline
\end{tabular}

*Statistically Significant

Figure-1: Comparison of Intubation time (in sec) of patients in Group A and Group B

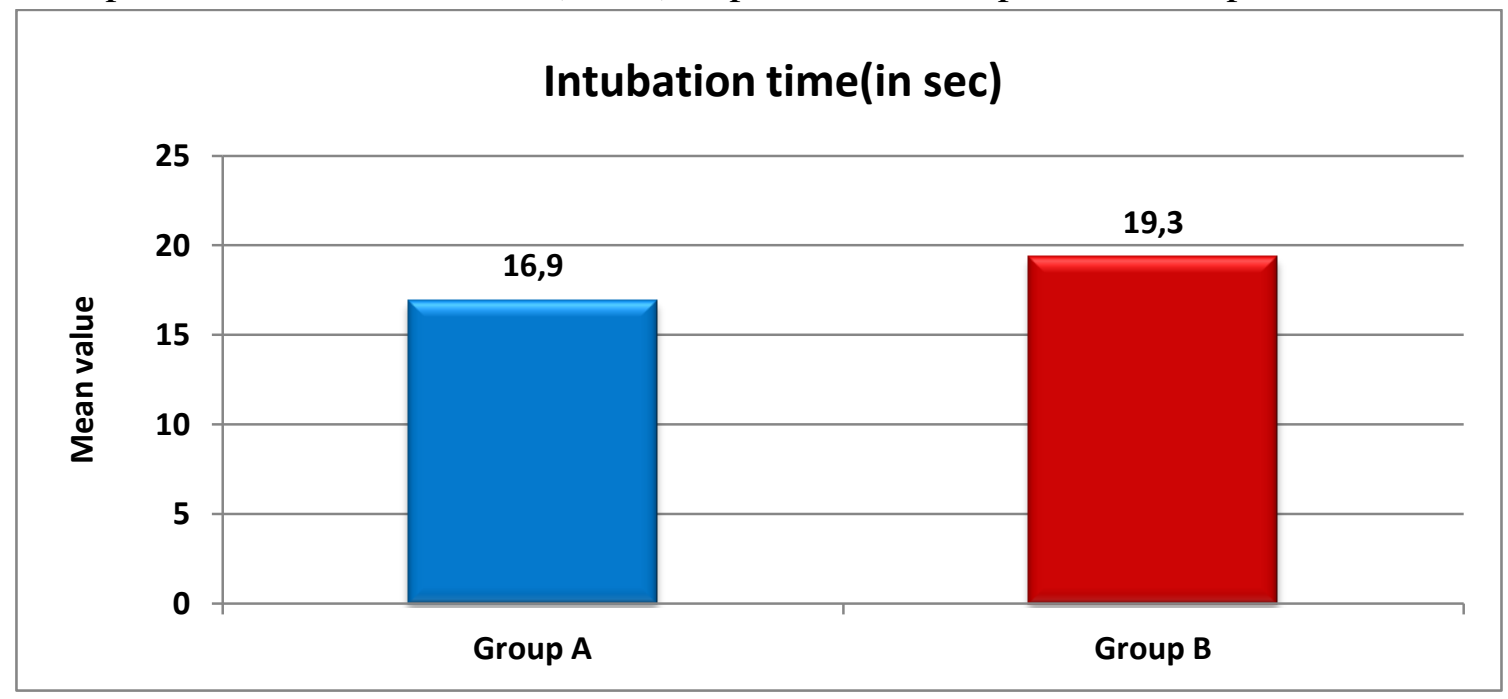




\section{JMSCR Vol||08||Issue||11||Page 308-315||November}

Figure-2: Comparison of POGO Score of patients in Group A and Group B

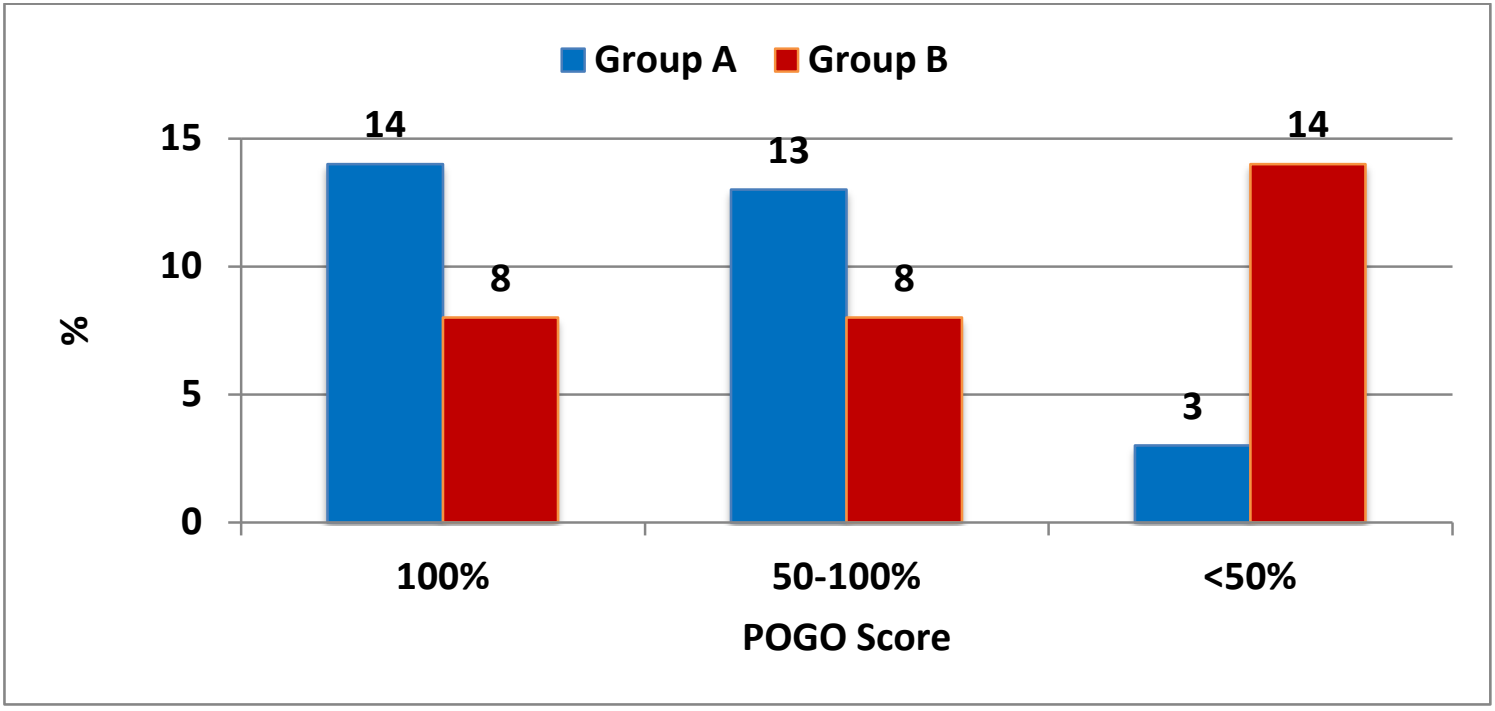

Figure 3: Comparison of IDS of patients in Group A and Group B

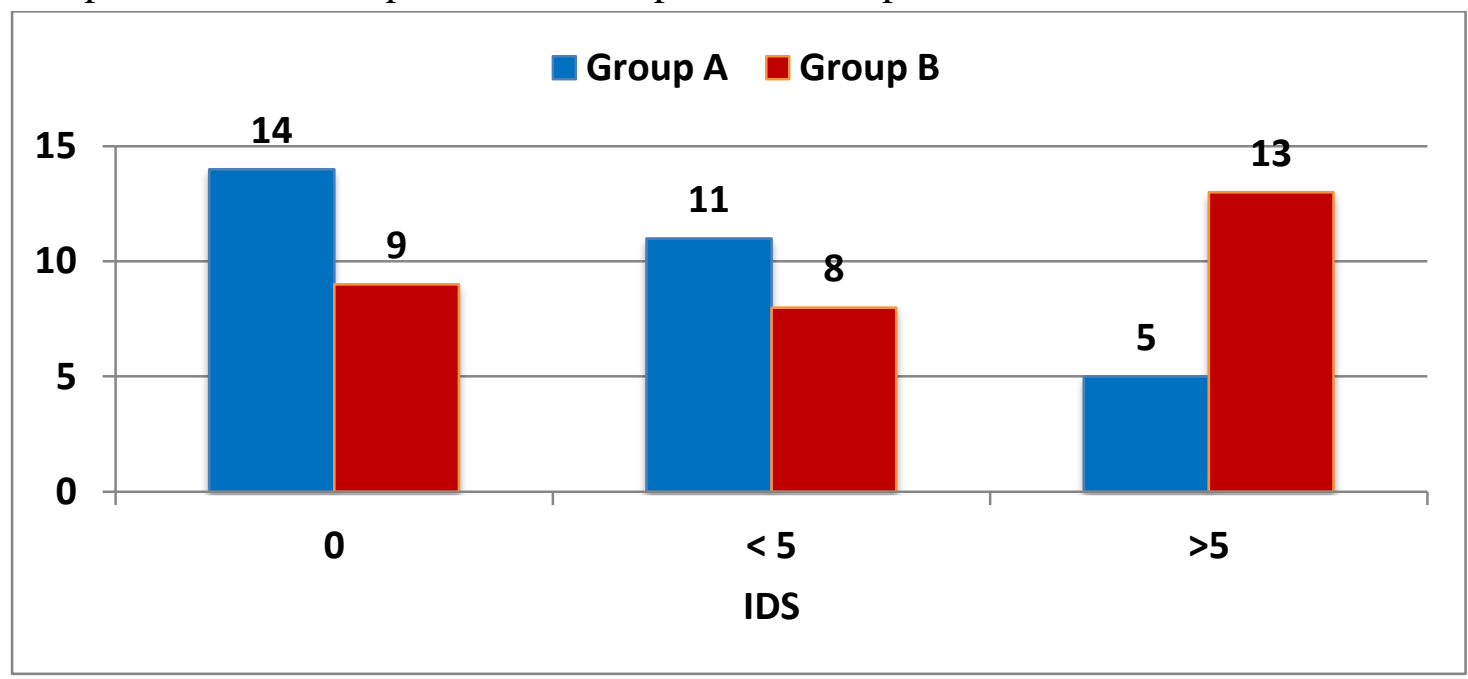

Figure 4: Comparison of mean arterial pressure at different time interval Between Group A and Group B

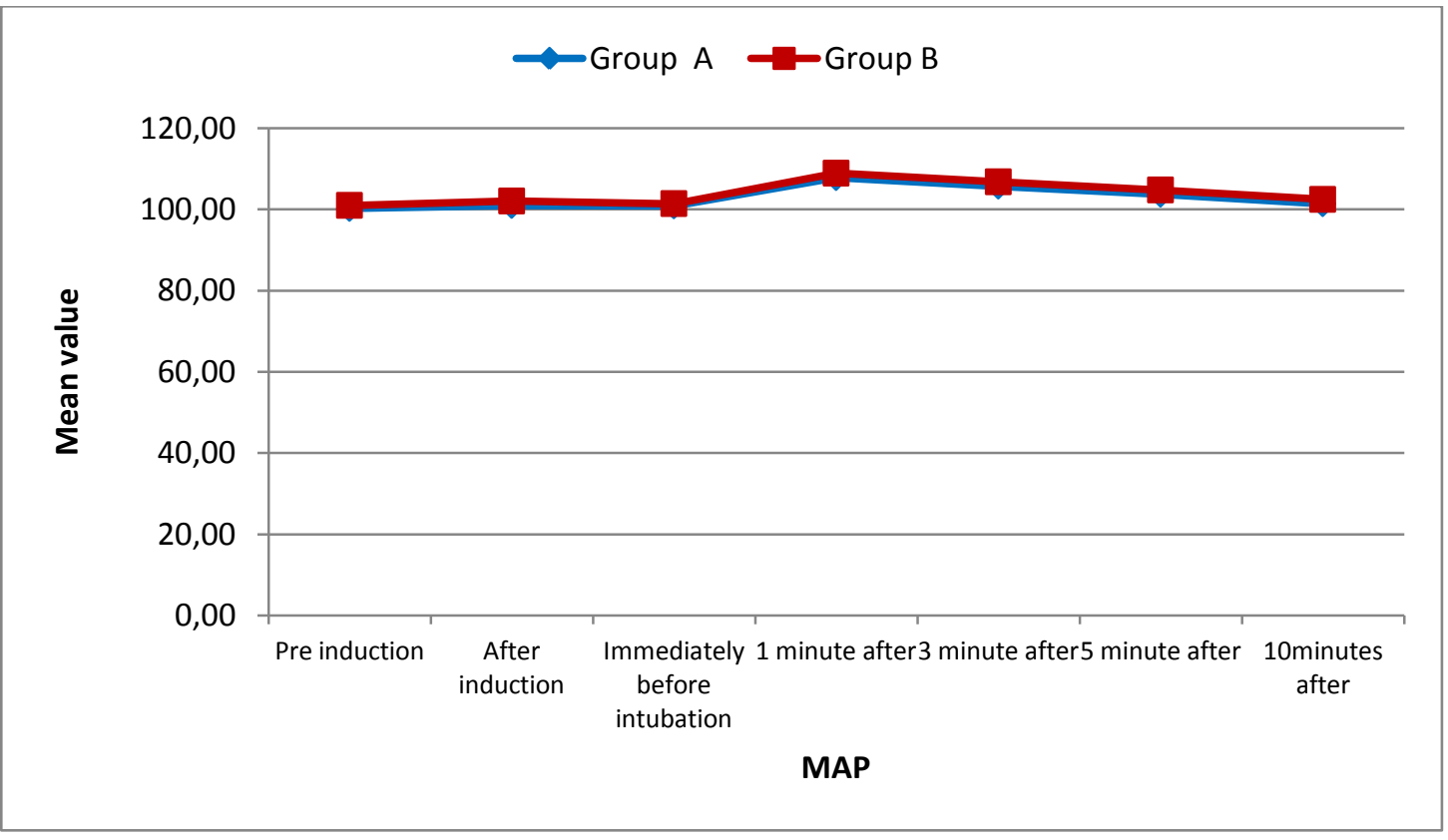




\section{Discussion}

The increase in trauma patients across the world and the need of intubation in cervical injury patients is in demand. The application of cervical collar or Manual inline stabilization reduces mouth opening and the application of other manoeuvres increases the risk of trauma. So, this study was conducted for understanding the visualization of glottis, successful intubations, number of attempts, trauma occurred and hemodynamic response during intubation in cervical immobilized patients with King Vision video laryngoscope and McCoy laryngoscope.

The demographic variables such as age, sex and ASA were similar in both the groups. There was no statistically significant difference. (Table -1 )

In our study the mean intubation time of patients in Group A was less $(16.9 \pm 3.5 \mathrm{sec})$ when compared with Group B patients $(19.3 \pm 5.1 \mathrm{sec})$. The difference in mean of Intubation time of patients in between these two groups was statistically significant $(p=0.021)$. ( Figure -1$)$

In accordance with the results of our study, Biswal D et $\boldsymbol{a l}^{6}$ also had similar results in their study where the mean intubation time was faster with the King Vision video laryngoscope (22.64 $\pm 2.63 \mathrm{sec}$ ) in comparison with the McCoy laryngoscope $(24.98 \pm 2.84 \mathrm{sec}), \quad(p=0.0016)$. Shravanalakshmi D et al $^{7}$, Ahmad S et al ${ }^{8}$, Singhal $\mathbf{V}$ et $\boldsymbol{a l} \boldsymbol{l}^{10}$ also had similar results.

The 1st attempt success rate in Group A was 97\% and Group B was $93 \%$ and the 2nd attempt success rate was $100 \%$ in both the Groups. 29 patients proceed in 1st attempt and 1 in 2nd attempt in Group A out of 30 patients and 28 patients proceed in 1 st attempt and 2 in 2 nd attempt in Group B out of 30 patients. There was no statistically significant difference in number of attempts of successful intubations. $(p=0.553)$. (Table - 2)

In accordance with results of our study, Biswal D et $\boldsymbol{a} \boldsymbol{l}^{6}$ had demonstrated similar results where the 1st attempt success rate was $93.3 \%$ (28/30) with King Vision video laryngoscope and 70\% (21/30) with McCoy laryngoscope. The similar results were also demonstrated by Ali $\mathbf{Q}$ et $\boldsymbol{a l}^{9}$, Shravanalakshmi D et $\boldsymbol{a l}^{7}$ and Ahmad S et al $\boldsymbol{l}^{8}$.

There was no change in performer required in Group Apatients but once the change of performer was required in 2nd attempt in Group B patients. Only one case of mucosal trauma was seen with Group B patients. (Table -2)

In our study out of 30 patients 14 patients have $100 \%$ POGO score , 13 have $50-100 \%$ and 3 have $<50 \%$ POGO score in Group A and out of 30 patients 8 patients have $100 \%$ POGO score ,8 have $50-100 \%$ and 14 have $<50 \%$ POGO score in Group B. There was significant difference in POGO score of patients in between Group A and Group B $(p<0.001)$. (Figure -2$)$

The study done by Biswal D et $\boldsymbol{a l}^{6}$ the mean POGO score of $95.53 \pm 17 \%$ with the King vision video laryngoscope as compared to the $79.9 \pm 31.23 \%$ with McCoy laryngoscope $(p=0.019)$ showed that King Vision provides better visualization of glottis. Almost similar results were obtained by Ali $\mathbf{Q}$ et al ${ }^{9}$, Shravanalakshmi D et $\boldsymbol{a l}^{7}$ and Ahmad S et $\boldsymbol{a l}^{8}$ in their studies.

In this study out of 30 patients in Group A, 14 patients have 0 IDS 0,11 have < 5 IDS score and 5 have $>5$ IDS and out 30 patients in Group B, 9 patients have 0 ID, 8 have < 5 IDS and 13 have > 5IDS. There was no statistically significant difference in IDS of patients in between Group A and Group B ( $p=0.077)$. Over all, the IDS score of Group A was reduced as compared to Group B. (Figure - 3)

Similar results were also observed byAli $Q$ et $\boldsymbol{a l} \boldsymbol{l}^{\boldsymbol{9}}$, with the IDS score zero in $43.3 \%$ (13/30) patients in King Vision video laryngoscope group which had significantly lesser scores in comparison to McCoy laryngoscope group with IDS score zero in $26.6 \%(8 / 30)$ patients $(p=0.001)$.

In a study by Shravanalakshmi D et $\boldsymbol{a l}^{7}$ the IDS score zero was seen in $68.8 \%$ (31/45) patients in King Vision video laryngoscope group in comparison to D blade of C-MAC video laryngoscope group where IDS score zero was 
seen in $53.3 \%(24 / 45)$ patients respectively. ( $p=$ 0.001).

There was no significantly statistical difference in the mean arterial pressure of two groups. In support of our study similar results were demonstrated by Ali $\mathbf{Q} \boldsymbol{e t} \boldsymbol{a l} \boldsymbol{l}^{\mathbf{9}}$ in his study where the heart rate and mean arterial pressure was increased after intubation and returned back to base line within 5 minutes but intubation time was less in the King Vision video laryngoscope group as compared to McCoy laryngoscope group. The similar results were also seen in studies by Biswal D et $a l^{6}$, Ahmad S et $a l^{8}$ and Singhal $\mathrm{V}$ et $a \boldsymbol{l}^{10}$.(Figure - 4)

\section{Conclusion}

The present study concluded that decreased intubation time, good visualization of glottis, successful intubations in 1st attempt, overall success rate and reduced IDS is seen in Group A in comparison of Group B. The hemodynamic response during intubation in cervical immobilized patients has least effect in Group A (King Vision laryngoscope) as compared to Group B (McCoy laryngoscope). So, we may conclude that the King Vision video Laryngoscope is proved to be superior then the McCoy laryngoscope if cervical immobilization is anticipated.

\section{References}

1. Ahmed SM, Ajmal PM, Ali S and Athar M. A Comparative Evaluation of C-MAC Video Laryngoscope and King Vision Video Laryngoscope in Patients Undergoing Tracheal Intubation with Cervical Spine Immobilization: A Prospective Randomized Study. Austin J Anesthesia and Analgesia. 2018; 6(1): 1066.

2. Apfelbaum JL, Hagberg CA, Caplan RA, Blitt CD, Connis RT, Nickinovich DG, Benumof JL, Berry FA, Bode RH, Cheney FW, Guidry OF. Practice guidelines for management of the difficult airwayan updated report by the American Society of Anesthesiologists task force on management of the difficult airway. The Journal of the American Society of Anesthesiologists. 2013 Feb 1;118(2):25170.

3. Goutcher CM, Lochhead V. Reduction in mouth opening with semi-rigid cervical collars. British journal of anaesthesia. 2005 Sep 1;95(3):344-8.

4. Heath KJ. The effect on laryngoscopy of different cervical spine immobilization techniques.Anaesthesia.

1994 Oct;49(10):843-5.

5. Uchida T, Hikawa Y, Saito Y, Yasuda K. The McCoy levering laryngoscope in patients with limited neck extension.Canadian Journal of Anaesthesia. 1997 Jun 1;44(6):674-6.

6. Biswal D, Pradhan BK, Hari Shankar R. A Comparative Evaluation of the Hemodynamic Response and Ease of Intubation with King Vision Video Laryngoscope and Mccoy Laryngoscope in Patients Posted For Cervical Spine Surgery, Undergoing Tracheal Intubation for General Anaesthesia. Sch. J. App. Med. Sci., Mar 2018; 6(3): 1257-1263

7. Shravanalakshmi D, Bidkar PU, Narmadalakshmi K, Lata S, Mishra SK, Adinarayanan S. Comparison of intubation success and glottic visualization using King Vision and C-MAC videolaryngoscopes in patients with cervical spine injuries with cervical immobilization: A randomized clinical trial. Surgical neurology international. 2017;8.

8. Ahmad S, Ali QE, Jamal MK, Kamal S, Pal K. A Prospective Randomized Study to Compare and Evaluate King Vision Video Laryngoscope and McCoy Laryngoscope as Intubating Devices in Adult Patients. J Med Sci Clin Res. 2017 Mar 26;5(03):19319-26 
9. Ali Q, Amir SH, Ahmed S. A comparative evaluation of King Vision video laryngoscope (channelled blade), McCoy, and Macintosh laryngoscopes for tracheal intubation in patients with immobilized cervical spine. Sri Lankan Journal of Anaesthesiology. 2017 Jul 5;25(2).

10. Singhal V, Bhandari G, Shahi KS, Chand G. Comparative Study of Mccoy, Airtraq and King's Vision Videolaryngoscope in Simulated Difficult Laryngoscopy Using Rigid Neck Collar. Ann. Int. Med. Den. Res. 2020; 6(4):AN05-AN09. 